\title{
Justification of a Method for Determination of Gas Content in Coal Seams to Assess Degasification Efficiency
}

\author{
Tailakov Oleg V. \\ T.F. Gorbachev Kuzbass State Technical University, \\ Institute of Coal Federal Research Centre Coal and Coal \\ Chemistry SB RAS \\ Kemerovo, Russian Federation \\ tailakov@uglemetan.ru
}

\author{
Kormin Alexey N. ${ }^{\text {, }}$ Zastrelov Denis N. ${ }^{\mathrm{b}}$, Utkaev \\ Evgeniy A. ${ }^{\text {c }}$, Sokolov Sergey V. ${ }^{\text {d }}$ \\ Institute of Coal Federal Research Centre Coal and Coal \\ Chemistry SB RAS \\ Kemerovo, Russian Federation \\ akormin@uglemetan.ru, bastrelov@uglemetan.ru, \\ cutkaev@uglemetan.ru, dsokolov@uglemetan.ru
}

\begin{abstract}
- the article presents a set of methods to assess gas liberation from coal substance on stages of drilling and coal core extraction, free gas discharge and gas diffusion from coal in the course of its activation by mechanical disturbance. The issues of their use in the mining industry are discussed. The analysis of ways to measure the methane desorption rate (volumetric method) and reservoir properties of coal is provided. Patterns of quantitative and qualitative distribution of methane within a coal rock massif are considered for the purpose of getting full information about fluctuation of volume and relative portion of residue gas under the impact of weathering and mining operations. A novel approach is suggested for the determination of gas content in coal seams to assess the effectiveness of degasification, to specify ventilation schemes and parameters of mining workings as well as to establish critical depths for sudden coal and gas outbursts manifestation and power accumulation for their potential occurrence.
\end{abstract}

Keywords - gas content, desorption test, degasification efficiency of coal seams, lost gas, underground coal mining.

\section{INTRODUCTION}

Modern underground coal mining method is characterized by working off gassy coal seams with the use of highperformance mining equipment, the effectiveness of which depends on geological conditions and often limited by a gas factor [1, 2]. Much importance to increase volume of coal production and mining safety is given to improvement of systems and means of coal seams degasification, which is closely related to methane content in coal seams, that presents one of the factors determining the mining workings development, speed of coal faces advancing and industrial safety of coal mines in general [3].

To estimate methane content in coal seams direct and indirect methods are used. An analytical review of existing methods for determining gas content in coal seams indicates that one of the most common ways for that is the direct method based on coal sampling during exploration work with afterwards measuring of contained methane volumes [4-6]. At the same time due to the low reliability of used specially sealed core-gas collectors conventional sampling devices are used, and gas content calculation is carried out taking into account the correction factors from 1.1 to 1.25 , depending on the coal basin, which reduces assessment reliability of released gas volumes [7-9]. Also, during exploration wells drilling a method based on the continuous gas logging in washing liquid coming out of the well is used. At coal mines gas content is determined by means of gas emissions registration during boreholes drilling and gas shooting performed in development workings and in coal faces with applied calculation methods. Wherein consistent patterns of filtration properties changes in a coal rock massif stipulated by the mining procedure and resultant from mining pressure discharge from enclosed rocks are not considered.

\section{MAterials AND MethodS}

To improve the existing core sampling devices a core sampler of a novel design was developed that allows to select cores in underground workings while maintaining the thermodynamic parameters of selected coal samples close to the natural conditions. It is known that gas liberation rate during core sampling mainly depends on the temperature and nature of the coal differential porosity and the total amount of released methane - from the volatiles output $[6,7]$.

Therefore core sampler testing was carried out on coals with different physical and engineering properties and the effectiveness was estimated with a specification figures system

$$
\left\{\begin{array}{l}
B_{K}=\frac{h_{k}}{H_{C}} ; \\
K_{0}=\frac{d_{k}}{D_{c}} ; \\
k_{n}=\frac{d_{k}}{h} .
\end{array}\right.
$$

Here $B_{\kappa}-$ a recovered core; $K_{0}$ - a core generation factor suggested by prof. Brently; $k_{n}-$ a core reception coefficient; $h_{k}$ -the distance from a core reception place to downhole; $H_{c}$-the borehole length; $d_{\kappa}$ - the diameter of a drilled out core; $D_{c}-\mathrm{a}$ borehole diameter; $h-\mathrm{a}$ height of core reception [10-14]. 
TABLE I. Features of designed core samplers demonstrated during out drilling of coal samples with fortress factor $\mathrm{f}=0.7-2.2$ by the prof. Protodjakonov scale

\begin{tabular}{|c|c|c|c|c|c|c|c|c|}
\hline $\begin{array}{c}\text { A core } \\
\text { sampler type }\end{array}$ & Coal grade & $\begin{array}{l}\text { Out drilling time } \\
\text { for a core } T_{d}(\mathrm{~min})\end{array}$ & $K_{o}$ & $\overline{K_{0}}$ & $k_{n}$ & $\overline{k_{n}}$ & $B_{k}$ & $\overline{B_{k}}$ \\
\hline \multirow{3}{*}{ I } & Coke-caking $(K C)$ & $20-30$ & 0.50 & \multirow{3}{*}{0.58} & 1.52 & \multirow{3}{*}{1.48} & 67 & \multirow{3}{*}{70} \\
\hline & Long-flame gas (ДГ) & $12-20$ & 0.56 & & 1.45 & & 72 & \\
\hline & $\operatorname{Gas}(\Gamma)$ & $10-15$ & 0.7 & & 1.48 & & 70 & \\
\hline \multirow{3}{*}{ II } & Coking-caking (KC) & $18-20$ & 0.35 & \multirow{3}{*}{0.55} & 1.46 & \multirow{3}{*}{1.54} & 70 & \multirow{3}{*}{70.6} \\
\hline & Long-flame gas (ДГ) & $26-27$ & 0.62 & & 1.58 & & 70 & \\
\hline & $\operatorname{Gas}(\Gamma)$ & $13-14$ & 0.7 & & 1.6 & & 72 & \\
\hline \multirow{3}{*}{ III } & Coke-caking (KC) & $17-19$ & 0.45 & \multirow{3}{*}{0.60} & 2.0 & \multirow{3}{*}{2,08} & 75 & \multirow{3}{*}{78.3} \\
\hline & Long-flame gas (ДГ) & $25-27$ & 0.65 & & 2.1 & & 80 & \\
\hline & $\operatorname{Gas}(\Gamma)$ & $10-13$ & 0.7 & & 2.14 & & 80 & \\
\hline
\end{tabular}

In Table 1 and on Fig. 1 characteristics and their average values for three types of core samplers used, when drilling out samples with a coal strength factor of $\mathrm{f}=0.7-2.2$ are presented. The advantages of a type III core sampler are the simplicity of design, and the highest rate of a core sampling (up to 0.7). Wherein the time for drilling out a sample was $1,200-1,620 \mathrm{~s}$, the core length was $0.3 \mathrm{~m}$ and the core diameter was $0.062 \mathrm{~m}$. With the use of the type III core sampler 85 coal samples were selected on the basis of which the amount of released methane was assessed, depending on desorption time under normal atmospheric pressure and temperature for samples, that have different stages of metamorphism and physical properties (dispersion structure, porosity).

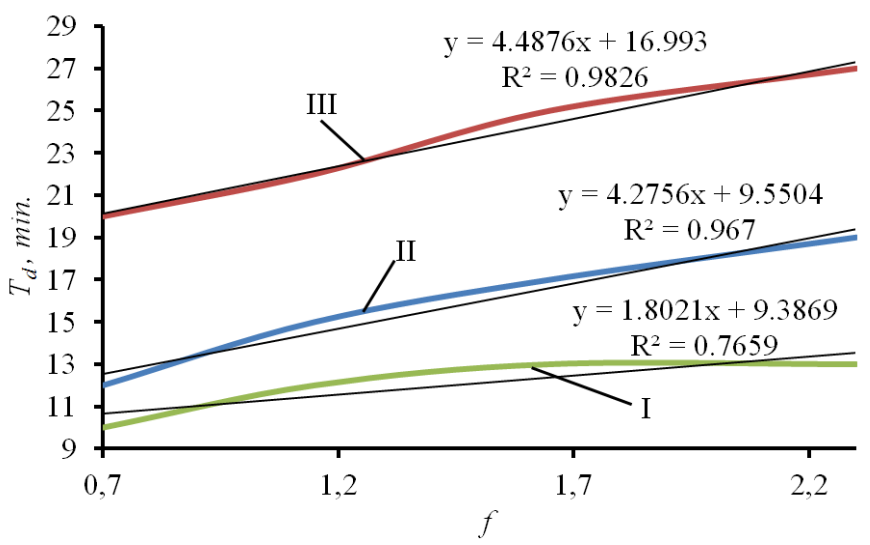

Fig. 1. Dependence of coal sample out drilling time $T_{d}$ against coal strength coefficient $f$, received in mine's conditions for coal of a long-flame gas ( $Д Г)$ grade when using I-III types core samplers

For the type I core sampler an average rate of core reception $\overline{k_{n}}$ is 10 to $15 \%$ lower compared to core samplers of II and III types. The time of a core out drilling with the use of a type III core sampler appears higher, which reduces the effect of rubbing and overheating of a coal sample, impacting preservation of its structure integrity.

The design of a core sampler type II envisages an inner cylinder for a set of samples, which allows to feed the washing liquid through drilling rods and thereby to cool down core sampler's walls in the process of core samples out drilling. Herewith the velocity of a core sample out drilling makes 720$1,200 \mathrm{~s}$ at a $0.3 \mathrm{~m}$ core length and $0.062 \mathrm{~m}$ diameter. In the type III unit drill bits on inner and outer cylinders of a core sampler were improved, that ensured the drilling speed between $1,200-1,620 \mathrm{~s}$. With a probability factor 0.17 a ratio of selected coal samples volumes to a sampler's inner chamber makes 0.98 . Fig. 2 shows a design of a mine core sampler type III intended for sampling from coal rock massif at any arbitrary distance from the side of a mining working.

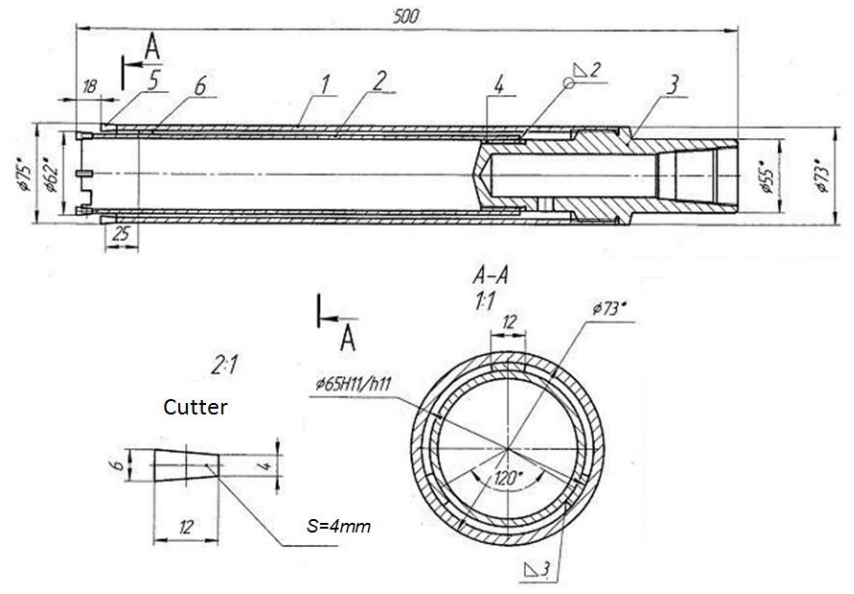

Fig. 2. Design of a core sampler for selection and transportation of coal samples:

1 - outer cylinder; 2 - core composing part;

3 - a shank for attachment to drill rods; 4 - a threaded joint; 5 - a drill bit; 6 - a centering unit

A core sampler delivery deep into the massif is done with drilling rods through a borehole, made with a drilling rig. The apparatus for coal cores sampling includes three units: a housing, a core reception chamber and a shank, which are interconnected with a double threaded join.

A core sampler design provides openings for coolant flowing through drill rods. For this type of a core sampler a principle of a mechanical device is generalized, based on cores sampling using a drill bit that breaks the rock radially.

The core sealing is done at the end of a core reception chamber of a 0.02-0.05 m length, which is formed directly in the downhole portion of the well. This core fragment is removed and is not used in subsequent measurements Undertaken mine's testing indicated the necessity to increase the time for cores out drilling on 480-600 s and to reduce the 
frequency of rotation up to $0.83 \mathrm{rvl} / \mathrm{s}$ because with vigorous rotation of a core sampler at 1.3-1.5 rvl/s a sample heating up to $70{ }^{\circ} \mathrm{C}$ takes place

\section{RESULTS AND DISCUSSIONS}

In the process of mining coal rock mass integrity disturbance happens which initiates a process of the methane mass transfer - its desorption into a low pressure area. It is known that methane molecules bond with coal is determined by Van der Waals forces, and methane discharge from a coal seam comprises two consecutive processes - filtration and diffusion [15-19]. The methane mass transfer through a system of open pores, fractures and channels communicating with the outer surface of the coal seam occurs by filtration. The process of methane molecules transferring from the area with high methane concentration to a low methane concentration one is called diffusion and is described by the Fick's second law, which takes into account spatial and temporal changes in methane concentration versus temperature. To determine the empirical forms of communication between gas content of coal samples with the time of gas content depletion a mathematical relation of methane filtration and diffusion was analyzed. Based on actual measurements the methane desorption process has been approximated by five mathematical functions [20]

$$
\begin{aligned}
& y=a_{0} e^{\left(b_{1} x\right)} \quad-\text { exponential relations; } \\
& y=b_{0}+b_{1} \times \ln (x) \quad-\text { logarithmic relations; } \\
& y=b_{0}+\frac{b_{1}}{x} \quad-\text { hyperbolic relations; } \\
& y=b_{0}+x^{b_{l}} \quad-\text { power level relations; } \\
& y=b_{o}+b_{1} x+b_{2} x^{2} \quad \text { - quadratic relations. }
\end{aligned}
$$

Here $a_{0}, b_{0} ; b_{1} ; b_{2}$ - parameters of regression curves; $y-$ released gas volume; $x=\sqrt{t} ; ; t$ - duration of the experiment (min).

Comparison of approximation quality was based on processing of experimental data measuring gas content of coal samples taken with application of the developed core sampler in mines of Kuznetsk coal basin (Kuzbass). The values of Fisher's criterion that actually characterizes the quality of approximations, reached 2.22 for the exponential relation; 3.72 - for the logarithmic ones; 2.27 - for the hyperbolic ones; 2.16 - for power level ones and 1.98 for the quadratic relations. Based on these results a conclusion was made that a gas desorption process is satisfactorily described with a logarithmic dependence at the determination coefficient of $R=$ 0.9 and can be represented as (Fig. 3)

$$
f(x)=\left\{\begin{array}{c}
a_{1}+b_{1} x ; x \in\left\lfloor x_{0} ; x_{\text {diff }}\right\rfloor \\
a_{2}+b_{2} \ln x ; x \in\left[x_{\text {diff }} ; x_{n}\right]
\end{array}\right.
$$

where $a_{1} ; b_{1} ; a_{2} ; b_{2}$ - parameters; $x_{0}=0 ; n$ - number of measurements; $x_{\text {diff }}-$ start of the diffusion; $\left[x_{0} ; x_{\text {star }}\right]-$ extrapolation interval; $\left[x_{\text {star }} ; x_{\text {diff }}\right]$ - filtration process (Darcy's law); $\left[x_{\text {diff }} ; x_{n}\right]$-diffusion process.

In laboratory studies, the lost volume of gas characterizing a coal sampling process during which the bleeding gas is not gathered into a sealed vessel, was determined by a backward extrapolation within the time moment $x=0$ (hereinafter, $x=\sqrt{t}, t-$ time of methane desorption from coal (min)).

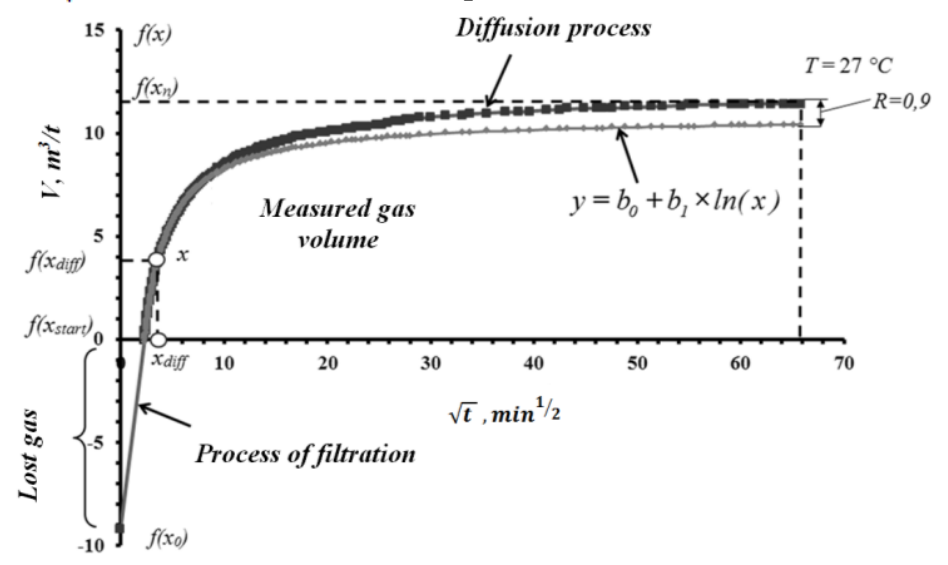

Fig. 3. The dependence of methane released volume $V$ against function of time $\sqrt{t}$

The volume of methane released within the range from $x_{\text {diff }}$ to $x$ is decreasing linearly, which is characterized as a process of filtration $[21,22]$.

Thus, when processing experimental data using the formula $y=k x+b$, it is possible to determine the position of the corresponding line. The volume of gas released in the second part of the desorption curve was measured within temperature ranges corresponding to natural conditions of coal seams bedding $\left(20-30{ }^{\circ} \mathrm{C}\right)$. But at the same time closed pores continued to retain $30-70 \%$ of gas volume, which characterizes the process of the inner gas diffusion [23].

As a result of executed measurements it was found that a gas diffusion process and gas filtering through the system of pores and fractures is slowed down in time. Thus at coal temperature $T=20-30{ }^{\circ} \mathrm{C}$ with volatiles output $V^{d a f}=37-43 \%$ the desorption time of methane enclosed within the open pores system and characterized as a process of gas filtration has made $t=300-600 \mathrm{~s}$ and at $V^{d a f}=71-85 \%, t=600-1.200 \mathrm{~s}$. A desorption curve describes the total volume of methane liberated by the time of gas depletion (900-1800 hours) from the studied coal sample. In a general case, the rate of gas pressure changes depends on the temperature of the sample, size of coal granules, coal permeability and a vessel volume. Thus, the defined peculiarities of a gas-kinetic process determine the possibility to use the mine core sampler of developed design for estimation of lost gas volume subsequent determination of gas content in coal seams of Kuzbass. 


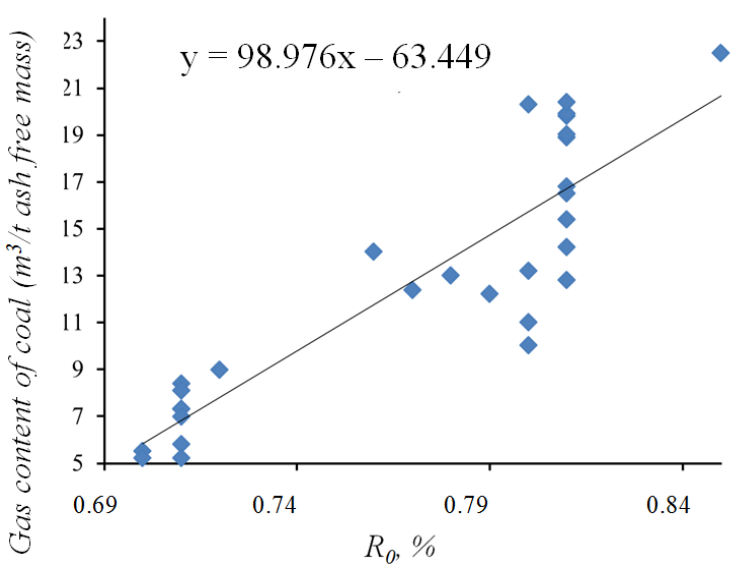

a)

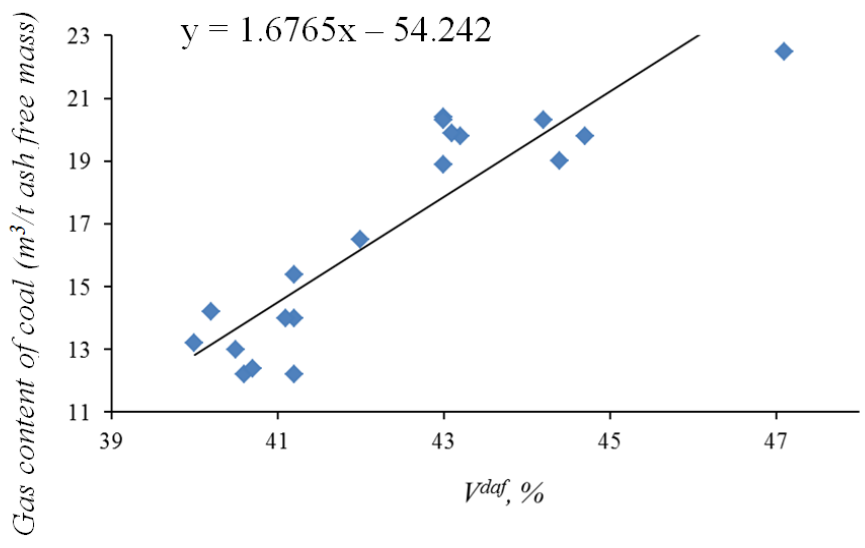

b)

Fig. 4. Gas content dependence $\chi$ on physical and technological properties of coal:

a) level of a vitrinite reflection $R_{0}=0.7 \div 0.9 \%$; b) volatiles output $V^{d a f}=40 \div 47.5 \%$

It is known that a portion of micro-organic inclusions in coal substance can range from 5 to $50 \%$ and it may influence on gas balance of enclosing rocks [24]. To determine the physical and chemical factors impacting the gas content of coal $\chi$, the analysis was performed indicating a gas content relation with volatiles output $V^{d a f}$ and with a vitrinite reflection index of $R_{0}$ (Fig.4).

It is determined that a methane filtration process continues for 600-900 s, after which it is transferred into a diffusion process under conditions that the pressure in a measuring system doesn't exceed $170 \mathrm{kPa}$ for Kuzbass types of coal. Laboratory measurements have shown that a slope ratio of the linear portion of the desorption curve corresponding to the Darcy's law, during gas filtration from a fractured-porous space of selected coal samples was 1.2-4.5. Wherein a volume of lost gas is well defined on the basis of a backward extrapolation method within the boundaries of this site. It was found that the uneven spatial distribution of gas content in coal was caused by the anisotropy of the carbon material components, which is characterized by a change in the volatile output $V^{\text {daf }}=37-43 \%$ and the degree of vitrinite reflection of $R_{0}=0.7-0.9 \%$, as well as by the presence of local irregularities in the coal seam structure.

\section{DISCUSSION}

On the basis of the obtained results it was revealed that the most important parameter affecting the gas content of the studied coal samples became the volatiles output Vdaf. It is suggested to use the dependence of gas content in coal on volatiles output (Fig. 4b) for verification of coal gas content values determined in the course of mining operations on the basis of the proposed approach.

To verify the obtained values of gas content in coal core samples taken in the mining workings a comparison of these values with the volatiles output was performed. It was found that a similar character of contours and iso gases derived from the performed measurements under real mining conditions with the use of the proposed approach, provided evidence for a satisfactory gas content assessment. With the help of the developed approach based on direct determination of gas content in coal, the effectiveness of degasification process of coal seams on four Kuzbass mines was undertaken (Table 2)

$$
K_{\text {эд }}=\frac{\chi_{n}-\chi_{n}^{\prime}}{\chi_{n}},
$$

where $\chi_{n}-$ in-situ gas content of the coal seam, $\left(\mathrm{m}^{3} / \mathrm{t}\right) ; \chi_{n}^{\prime}$ gas content after coal seam degasification $\left(\mathrm{m}^{3} / \mathrm{t}\right)$. The practical application of the developed approach for the definition of gas content of coal seams in Kuzbass mines is presented below. Fig. 5 shows changes of gas content in coal with regard of temperature conditions preservation in the range of $22-24^{\circ} \mathrm{C}$ on a coal seam 52 section identified with the use of the developed approach.

Based on the performed measurements it was defined that the coefficient of degasification efficiency for the considered mines fluctuated from 10 to $60 \%$ depending on the filtration properties of coal seams, and also under the impact of mining operations. The measurements in Kuzbass mines confirmed the possibility and feasibility of methods to assess gas content of coal in to be developed sections and in mining workings, as well as to monitor their degasification efficiency. Thus, the proposed method for estimation of methane content in coal under conditions of high intensity coal mining allows for the adoption of rational decisions on degasification of coal seams in the studied mines, including the use of gas content data of coal seams obtained during the development of mine's ventilation schemes. 


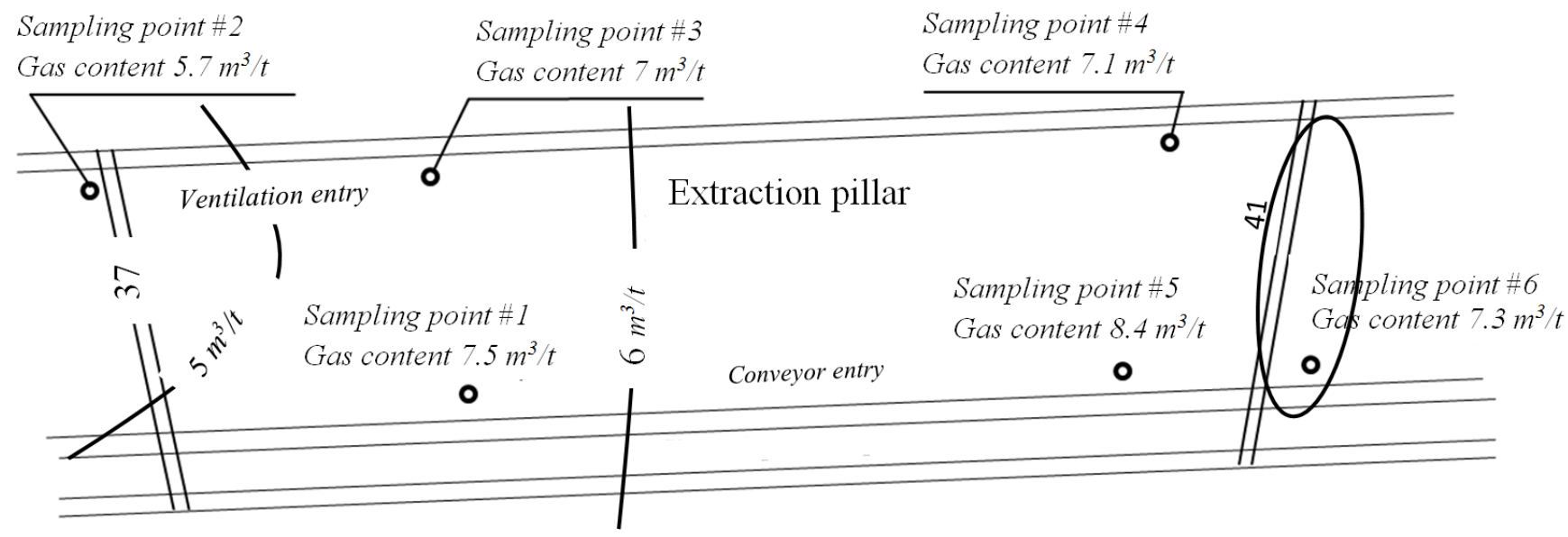

Fig. 5. Gas content of a coal seam and iso gases produced by means of the proposed method application and isolines of volatiles output, used for results verification

TABLE II. Estimate of degasification efficiency of coal seams based on the direct method

\begin{tabular}{|c|c|c|c|}
\hline Mine & $\begin{array}{c}\text { Coefficient of degasification } \\
\text { efficiency, }\left(K_{\text {ЭД })}\right.\end{array}$ & $\begin{array}{c}\text { In-situ gas content } \\
\left(\mathrm{m}^{3} / \mathrm{t} \text { of ash free mass }\right)\end{array}$ & $\begin{array}{c}\text { Residual gas content, } \\
\left(\mathrm{m}^{3} / \mathrm{t} \text { of ash free } \text { mass }\right)\end{array}$ \\
\hline A & $0.90-0.85$ & $9-14$ & $1.2-2.1$ \\
\hline B & $0.01-0.10$ & $9-11$ & $8.9-8.7$ \\
\hline C & $0.90-0.60$ & $17-20$ & $2.0-7.6$ \\
\hline D & $0.90-8.40$ & $18-20$ & $1.0-3.2$ \\
\hline
\end{tabular}

\section{CONCLUSION}

A method for evaluation of gas content in coal seams, that implies the use of a core sampler for sampling coal cores from wells drilled into the coal seam and subsequent measuring of gas amount liberated in the process of its desorption in laboratory conditions was developed. The proposed approach can be used directly to determine the methane content and to estimate coal seams degasification efficiency, to specify ventilation schemes and parameters of mining workings as well as to establish critical depths for manifestation and power accumulation for sudden coal and gas outbursts potential occurrence.

\section{REFERENCES}

[1] Dmitriev A.M. Problems of Gas Content in Coal Deposits /M.: Nedra. 1982. - $260 \mathrm{p}$.

[2] Kravtsov A.I. Gas Content of Coal Basins and Deposits in the USSR/Ch. Editor Vol. 3. Genesis and Regularities of Natural Gas Content in Coal Basins and Deposits of the USSR //M.: Nedra. - 1980. - 218 p.

[3] Tailakov O.V. Determination of Residual Gas Content of Coal Seams Based on Macrokinetic Desorption Processes of Filtration and Methane Diffusion to Assess the Effectiveness of Degassing/Tailakov O.V., Kormin A.N., Tailakov V.O. // Science and Technology in the Gas Industry. - 2014. - № 1 (57).- p. 10-13.

[4] Polevshchikov G.Y. Basics for Effective Development of Coal-Methane Deposits of Kuzbass / G.J. Polevshchikov, E.N. Kozyreva, M.V. Shinkevich, O.V. Bryuzgina // Vestnik Kuzbass. gosud. tehn. univ.-2011. - № 3. - p. 8-11.

[5] Tailakov O.V. Physical modeling of Fluid Filtration in the Coal Seam for Evaluating Skin Effect Radius / Tailakov O.V., Utkaev E.A., Zastrelov D.N., Smyslov A.I. // Mining Informational and Analytical Bulletin (Scientific and Technical Journal). - 2013.- № S6.- p. 165-169.

[6] A Guide to Coalbed Methane Reservoir Engineering. - Chicago, Illinois, USA.: GRI. - 1994. -307 p.
[7] Seidle J. Fundamentals of Coalbed Methane Reservoir Engineering /PennWell Corporation.- 2011.- 401 p.

[8] Kozyreva E.N. Gas Potentials of Developing Sections on Coal Methane Deposits, Peculiarities of their Distribution and Realization // Bulletin of Research Center for Safety in Coal Industry. - 2014. - № 1. - p. 109 113.

[9] Tailakov O.V. Development of Methods for Determining the Gas Content of Coal Seams in the Course of Mining Operations / Tailakov O.V. Mazanik E.V., Kormin A.N. // Mining Informational and Analytical Bulletin (Scientific and Technical Journal). - 2011.- № S8.- p. 210-214.

[10]Tailakov O.V. Physical Modeling of Filtration Properties Changes of Coal Seams / Tailakov O.V., Utkaev E.A., Kormin A.N., Smyslov A.I. // Vestnik Kuzbass. gosud. tehn. univ.. - 2014. - № 6.- p. 13-16.

[11] Yarovoi I.M., Beskrovnii V.I, Maslenko N.K, Chukaev I.P. Research on Methane Content of Coal Seams with Core and Gas Samplers DGI in the Mines of Western Donbass // Safety in Industry. - 1967. - № 2 - p. 40-41.

[12] Tailakov O.V. Development of Method of Rapid Analysis of Particle Size Distribution of the Coal Charge Based on Digital Image Processing / Tailakov O.V., Makeev M.P., Kormin A.N., Smyslov A.I. // Applied mechanics and materials. - 2015. - Vol. 770. - p. 512-517.

[13] Ponomarev P.P. Core Sampling During Core Exploration Drilling / Ponomarev P.P, Kaulin V.A. // L.: Nedra - 1989. - 256 p.

[14] Tailakov O.V. Evaluation of Coalbed Filtration Properties / Tailakov O.V., Smyslov A.I., Utkaev E.A. // Gasoilpress. - 2012. - № S672 (672). p. 24-25.

[15] Tailakov O.V. Peculiarities for Evaluation of Coalbed Methane Resources on the Example of Kuzbass / Tailakov O.V., Tailakov V.O., Zastrelov D.N., Kormin A.N. // Science and Technology in the Gas Industry 2015. - № 2. - p. 10-13.

[16] Tailakov O.V. Coalbed Methane: Development Prospects of International Cooperation in Kuzbass / Energy and Resources of Kuzbass. - 2001. - № 3.- p. 92-101.

[17]Koroljuk V.S. Handbook on Probability Theory and Mathematical Statistics / Koroljuk V.S., Porteko N.I, Skorokhod A.V., Turbin A.F. // M.: Nauka. - 1985. - 640 p.

[18] Tailakov O.V. Prospects for the Development of Extraction and Use of Coal Mine Methane in Kuzbass / Coal. -1998.- № 9. - p. 48-51.

[19] Gagarin S.G. Impact of Petrographic Indicators on Methane Sorption by coal // Coke and Chemistry. - 2007.- № 7. - p. 11-16. 
[20]Tailakov O.V. Definition of Gas Content of Coal Seams Based on the Study of Filtration Processes and Methane Diffusion / Tailakov O.V., Kormin A.N., Zastrelov D.N., Utkaev E.A. // Coal. - 2015. - № 1.- p. 74 77.

[21] Tailakov O.V. By the Estimation of Resources of Coal Mine Methane in the Goaf / Tailakov O.V., Tailakov V.O., Makeev M.P., Sokolov S.V., Kormin A.N. // Mining Informational and Analytical Bulletin (Scientific and technical journal). - 2013.- № S6.- p. 160-164.

[22] Vasyuchkov Yu.F. Physico-chemical Methods of Coal Seams Degasification / M.: Nedra - 1986. - 255 p.
[23] Ilnitskaya E.I.et.al. Properties of Rocks and Methods of Their Determination / M.: Nedra - 1969. - 147 p.

[24] Tailakov O.V. The method of Assessment of the Situation of Closed and Closed Mines Methane Gas (on the Example of the Severnay Mining Lease of the Mine) / Fedorin V.A., Tailakov O.V. // In: Ecological Problems of the Coal Mining Industry in the Region in the Transition to Sustainable Development.- Proc. of the International scientific-practical conference. 1999.- p. 179-186. 